\title{
Effect of Recreational Intervention on the Approach of Pediatric Patients in Dental Treatment: Analysis of Salivary Cortisol
}

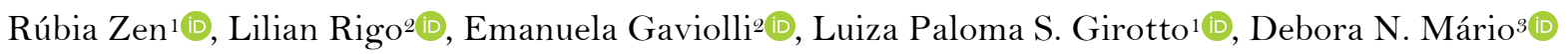

${ }^{1}$ School of Dentistry, Meridional Foundation, Passo Fundo, RS, Brazil.

${ }^{2}$ Postgraduate Program in Dentistry, Meridional Foundation, Passo Fundo, RS, Brazil.

${ }^{3}$ Federal University of Pampa, Uruguaiana, RS, Brazil.

Author to whom correspondence should be addressed: Prof. Lilian Rigo, Faculdade Imed, Rua Senador Pinheiro, 304, 99070-220, Passo Fundo, RS, Brazil. Phone: +55 54 3045-6100. E-mail: lilian.rigo@,imed.edu.br.

Academic Editors: Alessandro Leite Cavalcanti and Wilton Wilney Nascimento Padilha

Received: 01 May 2019 / Accepted: 27 January 2020 / Published: 19 February 2020

How to cite this article: Zen R, Rigo L, Gaviolli E, Girotto LPS, Mário DN. Effect of recreational intervention on the approach of pediatric patients in dental treatment: analysis of salivary cortisol. Pesqui Bras Odontopediatria Clín Integr. 2020; 20:e4796. https://doi.org/10.1590/pboci.2020.036

\begin{abstract}
Objective: To verify whether recreational interaction with pediatric patient before dental care influences cortisol levels and anxiety. Material and Methods: Twelve children were selected and divided into two groups: 6 children who had not previously received recreational intervention (Group I) and 6 children who received recreational intervention before dental care (Group II). Saliva was collected with Salivettes ${ }^{\text {TM }}$ kits before and soon after dental care for the measurement of cortisol. Wilcoxon test was applied to verify the difference in salivary cortisol levels before and after the dental visit in the whole sample, and the MannWhitney U test was used to analyze the difference between groups I and II. A significance level of 0.05 was considered. Results: Among patients from Group I, 3 had their cortisol levels increased after dental care, 2 had their cortisol levels decreased, and the other 1 patient remained constant. All participants from Group II had no significant difference in cortisol levels pre- and post-procedure. Mean salivary cortisol level was higher in Group I, pre- and post-procedure, compared to Group II. Conclusion: Pediatric patients who participated in an interactive activity prior to dental care have a lower level of anxiety according to the salivary cortisol levels obtained, compared to patients who did not participate in recreation. The techniques for the dentist to approach the child control the anxiety of the patient and make the procedure calmer and less stressful for both of them.
\end{abstract}

Keywords: Pediatric Dentistry; Hydrocortisone; Dental Anxiety; Stress, Psychological. 


\section{Introduction}

Chronic and early anxiety may lead to such deleterious effects of human physiological homeostasis that some authors regard as a public mental health problem [1]. It is estimated that about 3-16\% of adults suffer from dental phobia [2-5]. These values increase substantially in studies with pediatric patients [6]. The fear of going to the dentist is associated with a low frequency of dental visits, which ends up becoming a vicious circle, aggravating these two situations increasingly [7].

The success of child dental care is directly related to the pediatric dentist's ability to deal with the emotional issues of the patient [8]. Anxiety to dental treatment is the feeling aroused by situations related to the procedure that causes apprehension and discomfort, creating negative expectations in the patient. The most significant etiological factors for child dental fear and anxiety are negative attitudes and experiences of parents and their opinions about dental treatments [9]. Children go through different stages of psychological development, which must be known in order to determine their degree of learning and reasoning and understand their ability to adapt to the most diverse situations. The knowledge of psychology provides dentists with conditions to scientifically understand the behavioral problems that occur routinely in their offices, exposing the most appropriate way of solving them [10].

Biological parameters may contribute to a more accurate understanding of the problems related to anxiety and stress. Cortisol, known as the stress hormone, has been used as one of these parameters [11]. Cortisol is a steroidal glucocorticoid produced by the cortex of the adrenal gland. Its physiological secretion peaks in the morning as it prepares the body for daily stress [12]. Experimental models have shown that the physiological adaptive response to stress leads to the activation of the hypothalamic-pituitary-adrenal (HPA) axis, involving serum increase of the cortisol hormone [13]. However, the prolonged activation of this system may adversely affect important biological systems, leading to the dysregulation of the immune system and even the installation of disorders such as attention deficit hyperactivity disorder (ADHD) [14,15].

The dentist should be able to identify signs that may lead to the diagnosis of anxiety, especially in the pediatric patient, and from there on, to customize the approach of the child in order to avoid the aggravation of this feeling and future complications for their health [11].

Thus, this study aimed to evaluate child anxiety to dental treatment before and after dental procedures through the measurement of salivary cortisol levels. In addition, to analyze the influence of recreational interventions on the level of anxiety of children facing dental treatment.

\section{Material and Methods}

\section{Sample Qualification and Study Location}

Twelve children aged 5 to 10 years who were to undergo restoration were selected. Children presenting hormonal problems related to cortisol, cognitive deficits, psychiatric or psychological disorders, and children who had used corticosteroids up to 30 days before the dental visit were excluded. The selected children were randomly divided into two groups: a group of 6 children without pre-procedure recreational intervention (Group I) and a group of 6 children who received recreational intervention prior to treatment (Group II), resulting in a final sample of 12 children.

\section{Data Collection Procedures}

Saliva samples were collected using a Salivettes ${ }^{\text {TM }}$ kit (Sarstedt, Sarstedt Inc, Nümbrecht, Germany) to evaluate salivary cortisol concentration and, consequently, the anxiety level of children before and after 
dental care. Saliva was collected at two moments: before dental care and soon after the end of treatment. The collection of Group I was performed before dental care, in the waiting room of the dental clinic. Children were instructed to stay in the dental chair with the cotton from the kit under their tongue for about 60 seconds, removing it after that time and returning the cotton to the Salivette ${ }^{\mathrm{TM}}$ tube, followed by dentist procedure. After the procedure, the child remained in the dental chair and the second collection was performed the same way as before. The collection of Group II was performed in the waiting room before dental care, approaching children in an extroverted way, providing them with coloring sheets and pencils of various colors, with the intention to make them feel free to participate. After children began painting the drawings, they were instructed to introduce the cotton of the Salivette ${ }^{\mathrm{TM}}$ kit under their tongue for approximately 60 seconds while painting, removing it after that time and returning the cotton to the tube. The second collection was performed shortly after the end of dental care in the clinic. The volume of saliva obtained in this procedure was approximately 1 to 1.5 milliliters. Then, the samples were sent to the laboratory and analyzed by chemiluminescence assay (Elecsys and Cobasanalyzers ${ }^{\text {TM }}$, Roche Diagnostics International Ltd., Rotkreuz, ZG, Switzerland).

\section{Data Analysis}

Wilcoxon test was applied to verify the difference in salivary cortisol levels before and after the dental visit in the whole sample, and the Mann-Whitney $\mathrm{U}$ test was used to analyze the difference between groups I and II. A significance level of 0.05 was considered (GraphPad Software, San Diego, CA, USA).

Ethical Aspects

This study was approved by the Ethics Committee in Research under number 1.372.045. Parents or guardians who agreed with the inclusion of the children in the study completed and signed a free and informed con-sent. The children selected also agreed to participate in the study.

\section{Results}

In group I (without interaction), 3 of the 6 patients had their cortisol levels increased after dental care, 2 patients had their cortisol levels decreased, and the other 1 remained the same (Table 1). Group II (with preprocedure recreational interaction) showed no significant difference of pre- and post-procedure salivary cortisol concentration in $100 \%$ of the patients studied $(\mathrm{p}=0.051)$ (Table 1$)$.

Table 1. Salivary cortisol values $(\mu \mathrm{g} / \mathrm{dL})$ before and after dental care in patients who did not receive recreational interaction (Group I) and patients who received recreational interaction (Group II).

\begin{tabular}{|c|c|c|c|c|c|c|c|}
\hline $\begin{array}{l}\text { Patients } \\
\text { Group I }\end{array}$ & $\begin{array}{c}\text { Salivary } \\
\text { Cortisol } \\
(\mu \mathrm{g} / \mathrm{dL}) \\
\text { Pre- } \\
\text { procedure }\end{array}$ & $\begin{array}{c}\text { Salivary } \\
\text { Cortisol } \\
(\mu \mathrm{g} / \mathrm{dL}) \\
\text { Post- } \\
\text { procedure }\end{array}$ & p-value & $\begin{array}{l}\text { Patients } \\
\text { Group II }\end{array}$ & $\begin{array}{c}\text { Salivary } \\
\text { Cortisol } \\
(\mu \mathrm{g} / \mathrm{dL}) \\
\text { Pre- } \\
\text { procedure }\end{array}$ & $\begin{array}{c}\text { Salivary } \\
\text { Cortisol } \\
(\mu \mathrm{g} / \mathrm{dL}) \\
\text { Post- } \\
\text { procedure }\end{array}$ & p-value \\
\hline 1 & 0.067 & 0.226 & $<0.001^{*}$ & 7 & 0.064 & 0.060 & 0.051 \\
\hline 2 & 0.099 & 0.405 & $<0.001^{*}$ & 8 & 0.060 & 0.060 & 0.698 \\
\hline 3 & 0.196 & 0.113 & $<0.001 *$ & 9 & 0.060 & 0.060 & 0.698 \\
\hline 4 & 0.106 & 0.060 & $<0.001 *$ & 10 & 0.080 & 0.080 & 0.698 \\
\hline 5 & 0.110 & 0.220 & $<0.001 *$ & 11 & 0.060 & 0.060 & 0.698 \\
\hline 6 & 0.060 & 0.060 & 1 & 12 & 0.089 & 0.090 & 0.105 \\
\hline
\end{tabular}


Comparing means of Group I before and after treatment, there was a significant difference in cortisol levels $(\mathrm{p}<0.001)$, differently from the comparison of Group II before and after treatment, which showed no significant difference $(\mathrm{p}=0.492)$ (Figure 1). Comparing pre-procedure cortisol concentration between Group I and Group II, there was a significant difference ( $\mathrm{p}<0.001)$, with lower levels found in Group II (Figure 1). Similarly, comparing post-procedure cortisol of Group I and Group II, a significant difference $(p=0.001)$ was also observed, with higher values of cortisol for those in which no interactive activity was performed (Figure $1)$.

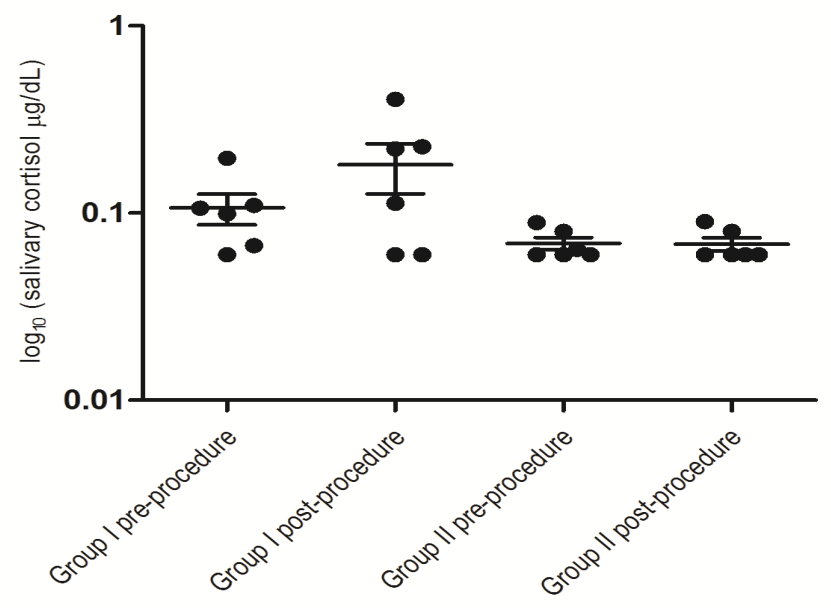

Figure 1. Distribution of salivary cortisol values $(\log 10 \mu \mathrm{g} / \mathrm{dL})$ before and after dental care in patients who did not receive recreational interaction (Group I) and patients who received recreational interaction (Group II).

\section{Discussion}

The present study evaluated the effect of recreation on the anxiety of children between 5 and 10 years before dental treatment, through the dosage of salivary cortisol. According to literary research, this is the first study that shows the importance of recreational techniques in dental practices, using a biological marker.

Child anxiety before and during dental care is frequent and acts as a barrier to treatment [16]. This becomes more exhausting for both children and professionals [11], which makes the treatment tedious and more complicated to be successfully performed [17]. The diagnosis of anxiety related to dental treatment may assist the dentist when approaching the child. After detecting the child's source of stress, the dentist can intervene to reduce this feeling. In the present study, we observed that mean cortisol level was higher in the group that did not receive recreational interaction before dental care compared to the values of the group that received interaction.

Child dental anxiety has been studied considering three main mechanisms: 1) direct conditioning, in which the child goes through a negative dental experience; 2) learning from negative personal experiences, stereotyped and possibly frightening views about dentistry, which are common in popular culture and relayed to children through family or colleagues; and 3) personality traits [18]. For controlling anxiety through nonpharmacological means, the dentist uses behavioral control techniques such as verbal communication, which is defined as the verbal expression of procedures, in which the patient is explained the procedures to be carried out according to his age and understanding. Non-verbal communication reinforces behavioral orientations 
through contact, posture, facial expression, and adequate body language. Thus, the child becomes familiar with dental procedures [19].

The use of recreational interactions with pediatric patients before dental care has divergent opinions of professionals [20]. However, recent studies have shown that different distraction techniques improve child behavior in these situations. In a previous research [21], as in the present study, the use of management strategies may favor the child's adaptation to treatment requirements. Regardless of technique and procedure to be performed, the patient needs a differentiated care, which justifies the choice to include in the present study a recreational interaction prior to care [22]. In the group that received recreational interaction, it was possible to observe that children remained quieter before and during treatment, confirmed by cortisol concentration, which remained constant before and after treatment.

In the present study, children aged between 5 and 10 years were included because authors report that age influences the occurrence of anxiety, and the pattern presented by children between 5 and 10 years old is different from that presented by children under 5 or over 10 years old $[11,16,17,23,24]$. Gender was not included as a variable for data collection, since studies report that gender is not associated with child anxiety regarding dental treatment [23]. Previous studies showed there is no major difference between invasive and non-invasive procedures from the child's behavioral point of view [24]. However, in the present study we selected similar procedures for both groups to eliminate any potential interference of the type of procedure with cortisol levels.

The present study evidenced the importance of recreational interventions to child care in the dental clinic, considering there was a significant difference in salivary cortisol levels in the group of children without intervention before treatment. In this group, 3 patients had increased cortisol concentrations after treatment. This may have been due to the child's lack of knowledge about the procedure and a potential association with the painful sensation experienced, or the long time demanded. In other 2 patients of this group, cortisol concentrations decreased after treatment. This may be explained by the negative expectation that was remedied by a peaceful and painless treatment.

Dental care anxiety has been diagnosed through validated scales/questionnaires in several studies conducted in different countries. Child patients or their caregivers may have difficulty understanding and completing self-administered questionnaires, or even feel embarrassed when asked about their emotional state. In addition, anxiety and stress questionnaires may reflect an inaccurate assessment of body condition [25]. Therefore, biological measures such as cortisol level may contribute to a more accurate understanding of the problems related to anxiety and stress [11]. In addition, authors state that salivary levels of cortisol may be used as biomarkers for stress and dental anxiety in children [26]. The collection of saliva for cortisol dosage, as the process performed in the present study, is considered a simple, non-invasive, and stress-free procedure, in addition to the samples remaining stable at room temperature for one week [11,27].

The negative consequences of defective cortisol secretion are generally greater when this disorder occurs in childhood [28]. Psychosocial stress may affect several immune functions controlled by the neuroendocrine system (hypothalamic-pituitary-adrenal axis), such as antibody secretion, helper $\mathrm{T}$ cell function, and macrophage and eosinophil reactivity [29,30]. Over time, hypersecretion of cortisol may lead to cortisol secretion at levels below normal as a function of the negative feedback process. Hypersecretion of cortisol and the concomitant decrease of the immune response have been associated with diseases such as depression, cancer, chronic inflammatory diseases, and increased susceptibility to infections $[13,15]$. 
The fear of dental care is still a cultural heritage passed from parents to children, which makes the first dental visit to rarely occur for prevention, but rather for necessity. The greatest challenge for pediatric dentists is controlling behavior and anxiety at the time of treatment, as professionals depend on it for successful procedures. Performing a very detailed anamnesis is required, seeking to know the patient as a whole, their past experiences, the environment they live in, and the dental experiences transmitted by their parents, so to recognize the cause of their fears and anxiety and if these are pathological or not. After knowing the patient, the first dental visit may feature conventional and non-pharmacological techniques, which are usually sufficient for a satisfactory treatment. If pathological anxiety is suspected in the pediatric patient, the cortisol dosage may aid diagnosis in order to initiate the appropriate treatment and avoid further consequences in adult life.

\section{Conclusion}

Pediatric patients who participated in an interactive activity prior to dental care have a lower level of anxiety according to the salivary cortisol levels obtained, compared to patients who did not participate in recreation. The techniques for the dentist to approach the child control the anxiety of the patient and make the procedure calmer and less stressful for both of them

\section{Authors' Contributions}

$\begin{array}{lll}\text { RZ } & \text { (D) OOOO-0001-7150-5717 } & \text { Methodology, Formal Analysis and Writing - Original Draft Preparation. } \\ \text { LR } & \text { (D) O000-0003-3725-3047 } & \text { Methodology and Validation. } \\ \text { EG } & \text { (D) 0000-0003-2039-1670 } & \text { Conceptualization, Investigation and Writing - Original Draft Preparation. } \\ \text { LPSG } & \text { (D) 0000-0002-7793-1773 } & \text { Conceptualization, Investigation and Writing - Original Draft Preparation. } \\ \text { DNM } & \text { (D) } 0000-0001-7021-3245 & \text { Formal Analysis and Writing - Original Draft Preparation. } \\ \text { All authors declare that they contributed to critical review of intellectual content and approval of the final version to be } \\ \text { published. }\end{array}$

\section{Financial Support}

No financial support.

\section{Conflict of Interest}

The authors declare no conflicts of interest.

\section{References}

[1] Crego A, Carrillo-Diaz M, Armfield JM, Romero M. From public mental health to community oral health: the impact of dental anxiety and fear on dental status. Front Public Health 2013; 2:16. https://doi.org/10.3389/fpubh.2014.00016

[2] Pohjola V, Rekola A, Kunttu K, Virtanen JI. Association between dental fear and oral health habits and treatment need among University students in Finland: a national study. BMC Oral Health 2016; 16:26. https://doi.org/10.1186/s12903-016-0179-y

[3] Quteish Taani DSM. Dental fear among a young adult Saudian population. Int Dent J 2001; 51(2):62-6. https://doi.org/10.1002/j.1875-595X.2001.tbo0823.x

[4] Appukuttan D, Subramanian S, Tadepalli A, Damodaran LK. Dental anxiety among adults: an epidemiological study in South India. N Am J Med Sci 2015; 7(1):13-8. https://doi.org/10.4103/1947-2714.150082

[5] Dou L, Vanschaayk MM, Zhang Y, Fu X, Ji P, Yang D. The prevalence of dental anxiety and its association with pain and other variables among adult patients with irreversible pulpitis. BMC Oral Health. 2018; 18:101. https://doi.org/10.1186/s12903-018-0563-x

[6] Nigam AG, Marwah N, Goenka P, Chaudhry A. Correlation of general anxiety and dental anxiety in children aged 3 to 5 years: a clinical survey. J Int Oral Health $2013 ; 5(6): 18-24$. 
[7] Armfield JM, Stewart JF, Spencer AJ. The vicious cycle of dental fear: exploring the interplay between oral health, service utilization and dental fear. BMC Oral Health 2007; 7:1. https://doi.org/10.1186/1472-6831-7-1

[8] Gereige RS, Dhepyasuwan N, Garcia KL, et al. Pediatric residents' knowledge and comfort with oral health Bright Futures concepts: a CORNET study. Acad Pediatr 2015; 15(5):551-6. https://doi.org/10.1016/j.acap.2015.04.036

[9] Anthonappa RP, Ashley PF, Bonetti DL, Lombardo G, Riley P. Non-pharmacological interventions for managing dental anxiety in children. Cochrane Database Syst Rev 2017; 2017(6):CD012676. https://doi.org/10.1002/14651858.CD012676

[10] Uman LS, Chambers CT, McGrath PJ, Kisely S. Psychological interventions for needle-related procedural pain and distress in children and adolescents. Cochrane Database Syst Rev 2006;(4):CD005179. https://doi.org/10.1002/14651858.CD005179.pub2

[11] Curcio WB, Scalioni FAR, Soares MRPS, Devito KL, Chaves MGAM, Ribeiro RA. Salivary cortisol levels in children undergoing dental treatment - a pilot study. Pesqui Bras Odontopediatria Clín Integr 2013; 13(1):5-10. https://doi.org/10.4034/pboci.v13i1.1410

[12] Hall JE. Guyton and Hall Textbook of medical physiology. 12 $2^{\text {th }}$. ed. Philadelphia: Saunders Elsevier; 2011.

[13] McEwen BS. Physiology and neurobiology of stress and adaptation: central role of the brain. Physiol Rev 2007; 87(3):873-904. https://doi.org/10.1152/physrev.00041.2006

[14] Adam EK, Kumari M. Assessing salivary cortisol in large-scale, epidemiological research. Psychoneuroendocrinology. 2009; 34(10):1423-36. https://doi.org/10.1016/j.psyneuen.2009.06.011

[15] van West D, Claes S, Deboutte D. Differences in hypothalamic-pituitary-adrenal axis functioning among children with ADHD predominantly inattentive and combined types. Eur Child Adolesc Psychiatry 2009; 18(9):543-53. https://doi.org/10.1007/s00787-009-0011-1

[16] Moura LA, Dias IM, Pereira LV. Prevalence and factors associated with preoperative anxiety in children aged 5-12 years. Rev Latinoam Enferm 2016; 24: e2708. https://doi.org/10.1590/1518-8345.0723.2708

[17] Padmanabhan V, Rai K, Hegde AM. Evaluation of stress during dental extractions using salivary cortisol levels and modified dental anxiety scales - a correlation study. Oral Health Dent Manag 2015; 14(2):175-8.

[18] Soares FC, Lima RA, Barros MVG, Colares V. Factors associated with dental anxiety in Brazilian children of 5 to 8 years. Braz Res Pediatr Dent Integr Clin 2014; 14(2):97-105. https://doi.org/10.4034/PBOCI.2014.142.04

[19] Goettems ML, Zborowski EJ, Costa FD, Costa VP, Torriani DD. Nonpharmacologic intervention on the prevention of pain and anxiety during pediatric dental care: a systematic review. Acad Pediatr 2017; 17(2):110-9. https://doi.org/10.1016/j.acap.2016.08.012

[20] Silva RD, Austregélio SC, Ithamar L, Lima LS. Therapeutic play to prepare children for invasive procedures: a systematic review. J Pediatr 2017; 93(1):6-16. https://doi.org/10.1016/j.jped.2016.06.005

[21] Sá Rocha RAS, Rolim GS, de Moraes ABA. Preparatory procedure for treating non-cooperative patients in pediatric dentistry). Acta Comport 2015; 23(4):423-5.

[22] Silva LFP, Freire NC, Santana RS, Miasato JM. Behavioral management techniques non-pharmacological in pediatric dentistry. Rev Odontol Univ Cid São Paulo 2016; 28(2):135-42.

[23] Góes MPS, Domingues MC, Couto GBL, Barreira AK. Anxiety, fear and vital signs of the child signs of the child patients. Odontol Clín-Cient 2010; 9(1):39-44.

[24] Cardoso CL, Loureiro SR. Children's behavioral problems and stress as a consequence of dental treatment anxiety. Estud Psicol 2005; 22(1):5-12. https://doi.org/10.1590/S0103-166X2005000100002

[25] Patil SJ, Shah PP, Patil JA, et al. Assessment of the changes in the stress-related salivary cortisol levels to the various dental procedures in children. J Indian Soc Pedod Prev Dent 2015; 33(2):94-9. https://doi.org/10.4103/0970-4388.155116

[26] McCarthy AM, Hanrahan K, Kleiber C, Zimmerman MB, Lutgendorf S, Tsalikian E. Normative salivary cortisol values and responsivity in children. Appl Nurs Res 2009; 22(1):54-62. https://doi.org/10.1016/j.apnr.2007.04.009

[27] Castro M, Moreira AC. Salivary cortisol on the evaluation of the hypothalamic-pituitary-adrenal axis. Arq Bras Endocrinol Metabol 2003; 47(4):358-67. https://doi.org/10.1590/So004-27302003000400008

[28] Bakker L, Rubiales J, López M. School stress perception and circadian rhythm of cortisol in children with ADHD. Arch Neurocien 2012; 17(1):39-42.

[29] Lucin KM, Sanders VM, Jones TB, Malarkey WB, Popovich PG. Impaired antibody synthesis after spinal cord injury is level-dependent and is due to sympathetic nervous system dysregulation. Exp Neurol 2007; 207(1):75-84. https://doi.org/10.1016/j.expneurol.2007.05.019

[30] Schleimer RP, Bochner BS. The effects of glucocorticoids on human eosinophils. J Allergy Clin Immunol 1994; 94(2):1202-13. https://doi.org/10.1016/0091-6749(94)90333-6 